\title{
Determination of Particulate Matter Emissions from Cattle Feedlots Using Wind Trax and the Flux-Gradient Technique
}

\author{
Henry F. Bonifacio1, Ronaldo G. Maghirang2, Steven L. Trabue 3 , Laura L. McConnell4, \\ John H. Prueger ${ }^{3}$, Edna R. Bonifacio ${ }^{2}$ \\ ${ }^{1}$ Pasture Systems and Watershed Management Research Unit, USDA Agricultural Research Service, University \\ Park, PA, USA \\ ${ }^{2}$ Department of Biological and Agricultural Engineering, Kansas State University, Manhattan, KS, USA \\ ${ }^{3}$ National Laboratory of Agriculture and the Environment, USDA Agricultural Research Service, Ames, IA, USA \\ ${ }^{4}$ Bayer Crop Science, 2 T.W. Alexander Dr., Research Triangle Park, NC, USA \\ Email: rmaghir@k-state.edu
}

Received 6 January 2016; accepted 13 February 2016; published 16 February 2016

Copyright (C) 2016 by authors and Scientific Research Publishing Inc.

This work is licensed under the Creative Commons Attribution International License (CC BY). http://creativecommons.org/licenses/by/4.0/

(c) (i) Open Access

\section{Abstract}

Large commercial cattle feedlots are significant sources of particulate matter (PM) emissions. This research compared WindTrax and the flux-gradient technique in estimating emissions of PM with aerodynamic diameter $\leq 10 \mu \mathrm{m}\left(\mathrm{PM}_{10}\right)$ from cattle feedlots. Meteorological conditions were measured and $\mathrm{PM}_{10}$ concentrations were profiled vertically (i.e., 2.0 to $7.62 \mathrm{~m}$ ) at a large commercial beef cattle feedlot in Kansas from May through September 2011. Results show that between the two methods evaluated, WindTrax was least sensitive to changes in heights and number of heights used in the emission estimation, with calculated $\mathrm{PM}_{10}$ emission rates varying by up to $18 \%$ only. On the other hand, $\mathrm{PM}_{10}$ emission rates produced by the flux-gradient technique varied by almost $56 \%$ when changing either heights and/or number of heights in emission calculation. Both methods were sensitive to height settings, with their respective $\mathbf{P M}_{10}$ emission rates higher when the lowest height setting $(2.0 \mathrm{~m})$ was included. Calculating $\mathrm{PM}_{10}$ emission rates with the $7.62-\mathrm{m}$ height led to lower estimates for the flux-gradient technique but no significant change in estimates was observed for WindTrax. As demonstrated in this study, for the flux-gradient technique, settings for the lowest and highest heights were the most critical in emission estimation; exclusion of other heights in between showed only to $2 \%$ to $6 \%$ change in calculated $P_{M_{10}}$ emission rates. In general, the higher $\mathbf{P M}_{10}$ emission rates were obtained with the flux-gradient technique. However, eliminating the lowest height $(2.0 \mathrm{~m})$ in the calculation and, at the same time, using a specific set of formulations for the flux-gradient technique made its calculated $\mathrm{PM}_{10}$ emission rates slightly lower (but not significantly different) than those from WindTrax. 


\title{
Keywords
}

\author{
PM $_{10}$ Emission Rates, Cattle Feedlots, Emission Rate Estimation, WindTrax, Flux-Gradient \\ Technique
}

\section{Introduction}

Air pollutant emissions from concentrated animal feeding operations (CAFOs), such as large commercial cattle feedlots, are a major air quality concern because of their harmful effects on human health and the environment. Air pollutants emitted from cattle feedlots include ammonia $\left(\mathrm{NH}_{3}\right)$ [1] [2], hydrogen sulfide $\left(\mathrm{H}_{2} \mathrm{~S}\right)$ [3] [4], greenhouse gases (GHGs) such as nitrous oxide $\left(\mathrm{N}_{2} \mathrm{O}\right)$ [5] and methane $\left(\mathrm{CH}_{4}\right)$ [6], volatile organic compounds (VOCs) [7], and particulate matter (PM) [8] [9]. Assessing the potential impact of these air pollutants, individually or in combination, on downwind locations remains challenging because of several factors, including lack of accurate emission rate estimates and reliable emission estimation methods [10] [11]. To address this, the US Environmental Protection Agency (EPA) initiated the National Air Emissions Monitoring Study (NAEMS) in 2005 as a 2-yr study to measure air pollutant emission rates at several participating CAFOs for development of new and improvement of existing emission estimation methods [12] [13]. Beef cattle feedlots were not part of the NAEMS; in 2011, however, the EPA requested quality-assured PM and gaseous emission rates from CAFOs, which now included cattle feedlots, to supplement those collected through NAEMS [14].

In large beef and dairy cattle feedlots, the animals are typically confined in open dirt lots. For these CAFOs, emission estimation is challenging because direct measurement of emission rates is often not feasible. Because the open dirt lots are exposed to and influenced by the outside environment, determining emission rates requires accounting for the temporal and spatial variability of emission rates, surface heterogeneity and local meteorology.

Several methods can be used to estimate pollutant emission rates from area sources, such as feedlots: these include micrometeorological techniques [15], box models [16], and inverse dispersion models [1]. The authors of the present study were involved in a large air quality project that included estimation of PM emission rates from a large commercial beef cattle feedlot in Kansas. The PM emission rates for the cattle feedlot studied were determined using several estimation methods, which included AERMOD, WindTrax and the flux-gradient technique, and estimates were already presented in published companion studies [8] [17] [18]. In Bonifacio et al. [18], emission rates for total suspended particulates (TSP), PM with aerodynamic diameter $\leq 10 \mu \mathrm{m}\left(\mathrm{PM}_{10}\right)$, and PM with aerodynamic diameter $\leq 2.5 \mu \mathrm{m}\left(\mathrm{PM}_{2.5}\right)$ determined using the flux-gradient technique were presented. Compared to other previously published values for California and Texas feedlots, these determined emission rates were significantly lower than those reported by EPA [19] and Auvermann et al. [20] but were within range of others [21] [22].

The method applied in emission rate estimation is a critical factor that can contribute to differences among reported PM emission rates-others include feedlot management practices, PM sampling methods, and measurement designs (e.g., length of measurement period). In a companion study [17], $\mathrm{PM}_{10}$ emission rates determined by AERMOD and WindTrax were already compared. Although it was found that AERMOD produced higher emission rates, a very high linearity $\left(\mathrm{R}^{2} \geq 0.93\right)$ in calculated emission rates between AERMOD and WindTrax was observed, indicating the possibility of developing conversion factors [17]. In the present study, $\mathrm{PM}_{10}$ emission rates determined by WindTrax and the flux-gradient technique were compared using the same set of concentration and meteorological measurements employed in companion studies [8] [17]. Effect of measurement heights used on emission estimation with each method was also verified. Similar to the previous study, the possibility of development of conversion factors between these two methods was explored.

\section{Materials and Methods}

The $\mathrm{PM}_{10}$ concentrations and meteorological conditions were measured at a commercial cattle feedlot in Kansas. From these field measurements, $\mathrm{PM}_{10}$ emission rates were calculated with WindTrax via inverse dispersion analysis, and with the flux-gradient technique using estimated vertical $\mathrm{PM}_{10}$ concentration profiles and approximated $\mathrm{PM}_{10}$ eddy diffusivities. 


\subsection{Feedlot Description}

The feedlot studied is generally rectangular in shape and has approximate dimensions of 0.5 and $1.7 \mathrm{~km}$ in eastwest and north-south directions, respectively (Figure 1(a)). It has a total pen area of approximately $0.59 \mathrm{~km}^{2}$ (59 ha) designed for 30,000-head capacity. The feedlot is relatively flat, with median surface roughness of $4.0 \mathrm{~cm}$ [8] [15]. Measurements used in comparing WindTrax and the flux-gradient technique were taken from May through September 2011. Information on feedlot management practices affecting pen conditions, such as manure scraping and water application, and meteorological conditions during this 5-month period were presented in Bonifacio et al. [8].

\subsection{Field Instrumentation}

A three-dimensional sonic anemometer (Campbell Scientific, Inc., Logan, UT) was installed at a 5.3-m tower for measurement of micrometeorological conditions at the feedlot. Eddy covariance measurement was recorded at 15-min intervals and included measured variances and covariances of the three wind velocity components $\left(u_{x}\right.$, $\left.u_{y}, u_{z}\right)$ and air temperature $(T)$. Using formulations presented by Flesch et al. [23], corresponding friction velocity $\left(u_{*}\right)$, Monin-Obukhov length $(L)$ and surface roughness $\left(z_{o}\right)$ were first computed in 15-min intervals before being integrated into hourly values.

Measurements of $\mathrm{PM}_{10}$ concentrations were conducted at two locations simultaneously: 1) within the feedlot, approximately 400 and $200 \mathrm{~m}$ from the feedlot's north and west edges, respectively; and 2) at the sampling site north (5 $\mathrm{m}$ away from the fenceline) or south (800 $\mathrm{m}$ away from the fenceline) edge of the feedlot if the wind was coming from the north or south, respectively (Figure 1(a)). In computing net $\mathrm{PM}_{10}$ concentrations, measurement within the feedlot was used as downwind concentration and measurement at either north or south sampling site was used as upwind concentration, depending on wind direction. The $\mathrm{PM}_{10}$ concentrations within the feedlot were measured at four sampling heights: 2.0, 3.81, 5.34, and $7.62 \mathrm{~m}$ above the feedlot surface (Figure 1(b)). The $\mathrm{PM}_{10}$ concentration at the upwind sampling site was measured at the $2.0-\mathrm{m}$ height only due to limited equipment availability. The $\mathrm{PM}_{10}$ concentrations were measured using tapered element oscillating microbalance (TEOM) samplers (series 1400a, Thermo Fisher Scientific, East Greenbush, NY), a US EPA federal equivalent method for determining $\mathrm{PM}_{10}$ concentrations (designation No. EQPM-1090-079). Monthly routine maintenance (i.e., inlet cleaning, flow audit, and leak test) was performed on TEOM $\mathrm{PM}_{10}$ samplers to ensure quality of data collection. The TEOMs were operated to record $\mathrm{PM}_{10}$ concentrations at 20-min intervals. The 20-min downwind and upwind concentrations were integrated into hourly averages before computing net hourly $\mathrm{PM}_{10}$ concentrations. Calculation of $\mathrm{PM}_{10}$ emission rates were based on hourly data points that had measured downwind and upwind concentrations and positive calculated net concentrations.

\subsection{WindTrax}

WindTrax is based on a reduced transport equation given by:

$$
\frac{\partial C}{\partial t}+u_{x} \frac{\partial C}{\partial x}+u_{y} \frac{\partial C}{\partial y}+u_{z} \frac{\partial C}{\partial z}=0
$$

where the overall mass transport for concentration, $C$, is defined by convective mass transport in all directions ( $x$, $y, z)$ with corresponding velocity components held constant, and an accumulation term $(\partial C / \partial t)$ [24]. The method selected by the developers of WindTrax to solve Equation (2) is the backward Lagrangian stochastic (bLS) approach that describes the evolution of particle position and particle velocity in a backward time frame. The derivation of concentration equations using the bLS approach is explained in detail by Flesch et al. [25] and Flesch and Wilson [24].

WindTrax has an interface that enables mapping of the area source of interest and sampler locations using aerial image files [26]. The studied feedlot was mapped using available satellite imagery (MapQuest.com, Inc.). In this study, WindTrax simulation inputs included measured hourly net $\mathrm{PM}_{10}$ concentrations and meteorological parameters. From the meteorological inputs, WindTrax estimates other variables required in parameterization of the atmospheric surface layer based on formulations described in Crenna [27] and Flesch et al. [23]. In the simulation, the number of particle released was set to 50,000, which is the default value [26]. The $\mathrm{PM}_{10}$ emission rates calculated with WindTrax were also screened based on criteria described by Flesch et al. [28]. 

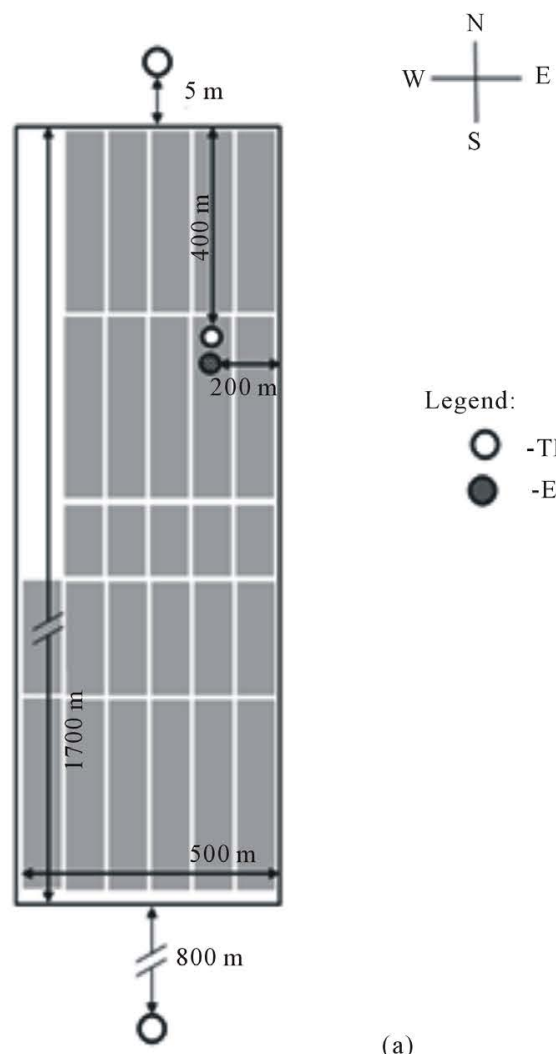

$$
\begin{aligned}
& \text { Legend: } \\
& \begin{array}{cl}
\mathrm{O} & \text {-TEOM } \mathrm{PM}_{10} \text { sampler } \\
\mathrm{O} & \text {-Eddy covariance tower }
\end{array}
\end{aligned}
$$

(a)

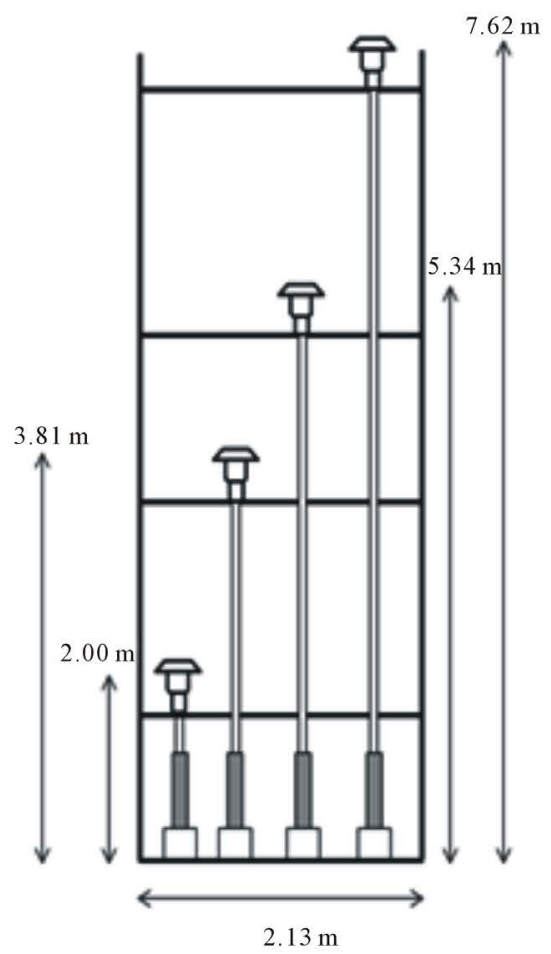

(b)

Figure 1. Field instrumentation: (a) location of sampling site within the feedlot, and (b) sampling heights for tapered element oscillating microbalance (TEOM) $\mathrm{PM}_{10}$ samplers. 
Measurement periods with very strong atmospheric stability $(|L|<10 \mathrm{~m})$, low wind speed $\left(u_{*}<0.15 \mathrm{~m} / \mathrm{s}\right)$, or unrealistic wind profile $\left(z_{o}>1 \mathrm{~m}\right)$ were considered unreliable and therefore not included in the comparison.

WindTrax can calculate emission rates using one or more concentration measurements [26]. Use of concentration measurements from several heights and locations, referred to as "overdetermined" simulation, is described to reduce the influence of concentration measurement errors on emission estimation, with the calculated emission rate the best fit for the given set of concentrations [26] [29]. In the present study, $\mathrm{PM}_{10}$ emission rates determined by WindTrax using single-height and multiple-height measurements were examined. But in comparing WindTrax and the flux-gradient technique, only the multiple-height measurements were used.

In McGinn et al. [9], $\mathrm{PM}_{10}$ emissions from Australian cattle feedlots was determined using a version of WindTrax modified to account for effects of gravitational settling on particle motion; however, this modified version still has to be made public. In the present study, the latest WindTrax version available (2.0.8.8, www.thunderbeachscientific.com) was used. Based on a companion study that used AERMOD [17], neglecting gravitational settling underestimated $\mathrm{PM}_{10}$ emission rates by $4 \%$.

\subsection{Flux-Gradient Technique}

For the flux-gradient technique, $\mathrm{PM}_{10}$ emission rate $\left(Q, \mu \mathrm{g} / \mathrm{m}^{2} \cdot \mathrm{s}\right)$ was calculated as:

$$
Q=-K_{P M} \frac{\mathrm{d} C_{m}}{\mathrm{~d} z}
$$

where $K_{P M}$ is $\mathrm{PM}_{10}$ eddy diffusivity $\left(\mathrm{m}^{2} / \mathrm{s}\right), C_{m}$ is measured net $\mathrm{PM}_{10}$ concentration $\left(\mu \mathrm{g} / \mathrm{m}^{3}\right)$, and $\mathrm{d} C_{m} / \mathrm{d} z$ is vertical $\mathrm{PM}_{10}$ concentration gradient $\left(\mu \mathrm{g} / \mathrm{m}^{3}-\mathrm{m}\right)$ [30] [31]. The vertical concentration gradient, $\mathrm{d} C_{m} / \mathrm{d} z$, was the derivative of the regression equation derived for sampling heights with concentration measurements [18]. In Bonifacio et al. [8], suitability of the flux-gradient technique in determining $\mathrm{PM}_{10}$ emissions from cattle feedlots had been verified using the criterion presented by Lilly [32]. Based on ratios of particle relaxation times calculated for different PM sizes to Lagrangian time scales measured at the studied feedlot, feedlot PM with aerodynamic diameter $<35 \mu \mathrm{m}$ is essentially governed by eddy diffusion [18], and thus, suggesting suitability of the fluxgradient technique for PM emissions within this size range.

The $K_{P M}$ was determined from eddy diffusivity for momentum, $K_{m}\left(\mathrm{~m}^{2} / \mathrm{s}\right)$, and Schmidt number, $S_{c}$ (Equation (3)) [33] [34].

$$
K_{P M}=\frac{K_{m}}{S_{c}}
$$

The $S_{c}$ was set to 0.63 , which was the overall value determined for $\mathrm{PM}_{10}$ emissions at the studied feedlot that had hourly median $S_{c}$ ranging from 0.40 to 1.23 [8]. The $K_{m}$ was given by:

$$
K_{m}=\frac{k u_{*} Z_{m}}{\phi_{m}}
$$

where $z_{m}$ is mean geometric height based on heights with $\mathrm{PM}_{10}$ concentration measurements, and $\phi_{m}$ is a nondimensional correction parameter that accounts for atmospheric stability effects [34]. Prueger and Kustas [31] provided a summary of different formulations that can be used in calculating $\phi_{m}$. With a general expression given by:

$$
\phi_{m}=\left(1+a \frac{Z_{m}}{L}\right)^{b}
$$

four sets of formulations for $\phi_{m}$ were used in this study, with values for $a$ and $b$ summarized in Table 1 . Selection of these formulations were based on its appropriateness for representing the feedlot surface: 1) Hogstrom [35] applies for multiple surface from oceans to forest and was the one used in the companion studies [8] [18]; 2) Flesch et al. [23] is the one implemented in WindTrax; 3) Dyer and Hicks [36] was derived for plowed field (i.e., with a loose surface layer like that of the feedlot surface); and 4) Hogstrom [37] has been used in a previous cattle feedlot study [38].

For the flux-gradient technique, two screening criteria were implemented. The first criterion required that the corresponding fetch of the uppermost sampling height $(7.62-\mathrm{m})$ fall within the feedlot boundary to ensure that 
Table 1. Values of parameters $a$ and $b$ in calculating the nondimensional correction parameter $\phi_{m}$ for the flux-gradient technique.

\begin{tabular}{|c|c|c|c|c|c|}
\hline \multirow[t]{2}{*}{$\phi_{m}$} & \multicolumn{2}{|c|}{ Stable atmospheric conditions } & \multicolumn{2}{|c|}{ Unstable atmospheric conditions } & \multirow[t]{2}{*}{ Reference } \\
\hline & $a$ & $b$ & $a$ & $b$ & \\
\hline 1 & 5.3 & 1 & -19.0 & -0.25 & Hogstrom [35] \\
\hline 2 & 5.0 & 1 & -6.0 & -0.25 & Flesch et al. [23] \\
\hline 3 & 5.0 & 1 & -16.0 & -0.25 & $\begin{array}{c}\text { Dyer and Hicks [36] for unstable condition } \\
\text { Dyer [39] for stable condition }\end{array}$ \\
\hline 4 & 4.8 & 1 & -15.2 & -0.25 & Hogstrom [37] \\
\hline
\end{tabular}

calculated emission rates represented $\mathrm{PM}_{10}$ emitted at the feedlot only and not from outside sources. Calculation of fetch was based on Hsieh et al. [40] as previously implemented in companion studies [8] [18]. The second criterion described the vertical concentration profiles appropriate for the flux-gradient technique, such that $\mathrm{PM}_{10}$ concentration should be linear and decreasing with the logarithm of height. Linearity between $\mathrm{PM}_{10}$ concentration and logarithm of height was assessed in terms of Pearson correlation. Preliminary analyses showed that increasing the Pearson correlation criterion lowered the difference in calculated $\mathrm{PM}_{10}$ emission rates between WindTrax and the flux-gradient technique but greatly decreased the number of hourly data points for comparison. With the flux-gradient technique producing higher emission rates, Pearson correlation criteria of $0.75,0.85$, 0.95 , and 0.975 resulted to differences of $31 \%, 28 \%, 20 \%$, and $19 \%$, respectively, in calculated $\mathrm{PM}_{10}$ emissions between the two methods based on 228, 184, 104, and 58 hourly data points, respectively. Based on these results, a Pearson correlation criterion of 0.95 was implemented for the flux-gradient technique.

\subsection{Data Analyses}

In this study, analyses include: 1) for each emission estimation method, comparison of $\mathrm{PM}_{10}$ emission rates derived using data sets that differed in heights and number of heights included (Table 2); and 2) comparison of $\mathrm{PM}_{10}$ emission rates calculated with WindTrax and the flux-gradient technique. For WindTrax, $\mathrm{PM}_{10}$ emission rates estimated using single-height measurements (i.e., data sets 7 and 8) was also verified. Linear regression analyses were performed in comparing any two $\mathrm{PM}_{10}$ emission rate estimates. In addition, paired t-test was done when comparing $\mathrm{PM}_{10}$ emission rates of WindTrax and the flux-gradient technique. In the comparison, a 5\%significance level was applied. For hourly net $\mathrm{PM}_{10}$ concentrations, overall values were reported as averages. But due to its skewed and asymmetric distributions, $\mathrm{PM}_{10}$ emission rates were reported as medians.

\section{Results and Discussion}

A total of 74 hourly data points passed the screening criteria defined for both methods and was included in all data sets used in the comparisons (Table 2). Based on calculated $L$, 70 of these data points had unstable atmospheric conditions. In terms of time of the day, numbers of hourly data points were 7, 20, 27, and 20 for the 0100 $\mathrm{h}$ to $0600 \mathrm{~h}, 0700 \mathrm{~h}$ to $1200 \mathrm{~h}, 1300 \mathrm{~h}$ to $1800 \mathrm{~h}$, and $1900 \mathrm{~h}$ to 2400 periods, respectively.

\subsection{Net $\mathrm{PM}_{10}$ Concentrations}

Hourly average net $\mathrm{PM}_{10}$ concentrations are shown in Figure 2. The $\mathrm{PM}_{10}$ concentrations at all four sampling heights exhibited diurnal trends, with the highest concentrations measured during the early evening period, which started to increase at $1900 \mathrm{~h}$ and ended at $2300 \mathrm{~h}$, and the lowest during early morning period $(0200 \mathrm{~h}$ to $0300 \mathrm{~h}$ ) (note: no data point for $0400 \mathrm{~h}$ and $0500 \mathrm{~h}$ ). From the 74 hourly data points, average net $\mathrm{PM}_{10}$ concentrations were $305 \pm$ 351, $189 \pm$ 194, $142 \pm 145,107 \pm 117 \mu \mathrm{g} / \mathrm{m}^{3}$ for 2.0-, 3.81-, 5.34-, and 7.62-m heights. As shown in Figure 3, $\mathrm{PM}_{10}$ concentration had a very strong linear relationship $\left(\mathrm{R}^{2}=0.98\right)$ with the logarithm of sampling height (note: for illustration purposes, median concentrations and corresponding upper and lower standard deviations were used). On average, $\mathrm{PM}_{10}$ concentration decreased by $34 \pm 41 \mu \mathrm{g} / \mathrm{m}^{3}$ for every $1 \mathrm{~m}$ increase in height. Within the day, the highest vertical $\mathrm{PM}_{10}$ concentration gradient was measured from $1900 \mathrm{~h}$ to $2000 \mathrm{~h}$, in which the concentration decreased by $103 \pm 100 \mu \mathrm{g} / \mathrm{m}^{3}$ for every $1 \mathrm{~m}$ increase in height, whereas the 
Table 2. Description of data sets used in $\mathrm{PM}_{10}$ emission rate estimation using WindTrax and the flux-gradient technique. ${ }^{\mathrm{a}}$

\begin{tabular}{ccc}
\hline Data set & Number of heights & Heights (m) \\
\hline 1 & 4 & $2.0,3.81,5.34,7.62$ \\
2 & 3 & $3.81,5.34,7.62$ \\
3 & 3 & $2.0,3.81,5.34$ \\
4 & 2 & $3.81,7.62$ \\
5 & 2 & $2.0,7.62$ \\
6 & 2 & $2.0,5.34$ \\
$7^{\mathrm{a}}$ & 1 & 3.81 \\
$8^{\mathrm{a}}$ & 1 & 2.0 \\
\hline
\end{tabular}

a. For WindTrax only.

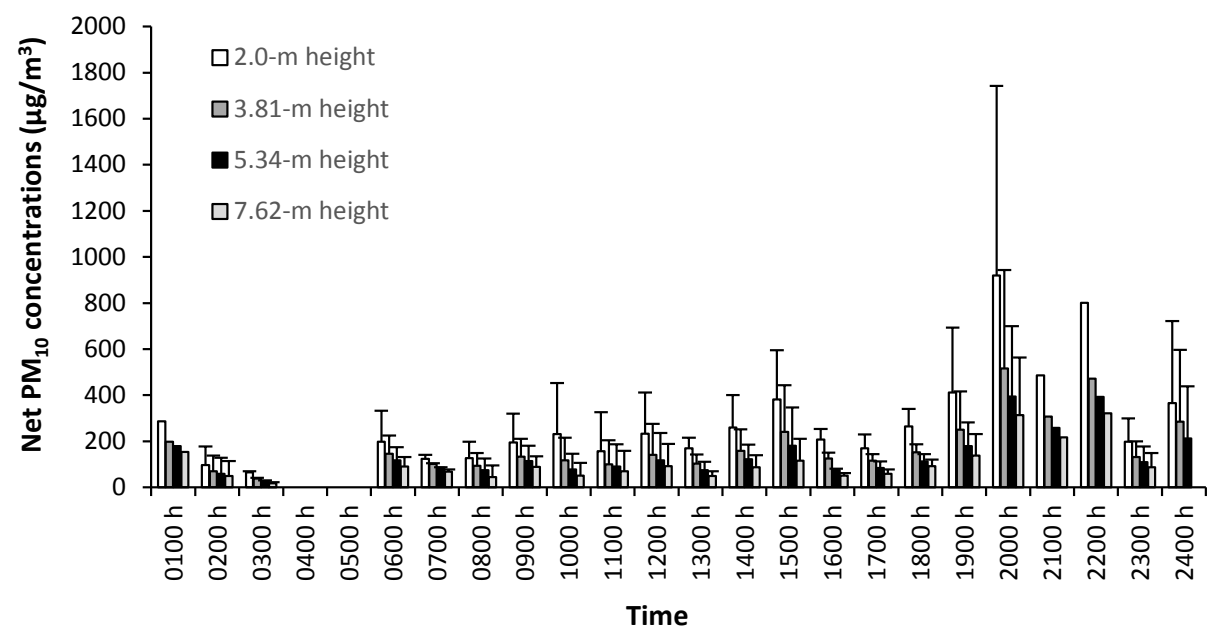

Figure 2. Hourly average net $\mathrm{PM}_{10}$ concentrations for the four measurement heights from May through September $2011(n=74)$. Error bars represent standard deviations.

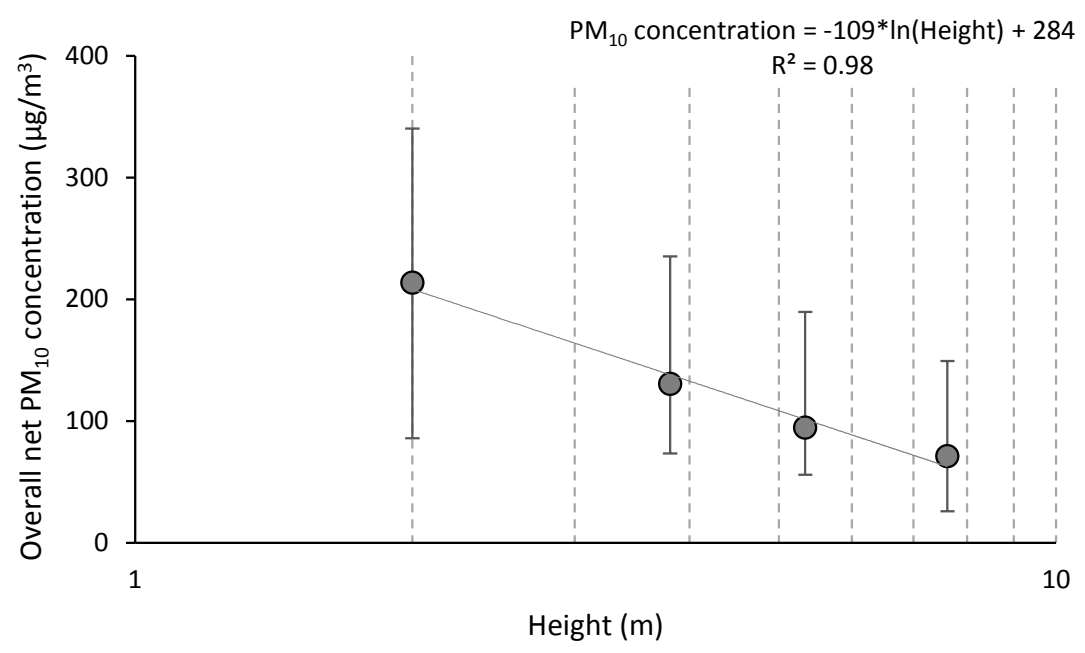

Figure 3. Plot of net $\mathrm{PM}_{10}$ concentrations against the logarithm of measurement heights $(n=74)$. Error bars represent upper and lower standard deviations. 
lowest was measured from $0100 \mathrm{~h}$ to $0300 \mathrm{~h}\left(8 \pm 1 \mu \mathrm{g} / \mathrm{m}^{3} \cdot \mathrm{m}\right)$.

\subsection{WindTrax-Based $\mathrm{PM}_{10}$ Emission Rates}

Ranges of hourly $\mathrm{PM}_{10}$ emission rates for the eight data sets are plotted in Figure 4. Diurnal trend in calculated $\mathrm{PM}_{10}$ emission rates was observed for all data sets, with the highest $\mathrm{PM}_{10}$ emission rates calculated for the $1900 \mathrm{~h}$ to $2200 \mathrm{~h}$ period ( 47 to $128 \mu \mathrm{g} / \mathrm{m}^{2} \cdot \mathrm{s}$ ), followed by the $1400 \mathrm{~h}$ to $1500 \mathrm{~h}$ period (50 to $80 \mu \mathrm{g} / \mathrm{m}^{2} \cdot \mathrm{s}$ ). Based on overall median hourly values, highest $\mathrm{PM}_{10}$ emission rates were obtained with data set 8 (i.e., 2.0-m height only), with a value of $37 \mu \mathrm{g} / \mathrm{m}^{2} \cdot \mathrm{s}$, followed by data sets $5,6,3$, and 1 with values of $34.8,33.6,32.8$, and $32.6 \mu \mathrm{g} / \mathrm{m}^{2} \cdot \mathrm{s}$, respectively. On the other hand, the lowest $\mathrm{PM}_{10}$ emission rates were calculated using data sets 2,4 , and 7 , with overall median values ranging from 29.1 to $30.5 \mu \mathrm{g} / \mathrm{m}^{2} \cdot \mathrm{s}$. These results indicate that use of the $2.0-\mathrm{m}$ height, which was the lowest sampling height, in determining hourly $\mathrm{PM}_{10}$ emission rates with WindTrax led to emission estimates higher by almost $27 \%$.

Slopes and $\mathrm{R}^{2}$ values from regression analyses are summarized in Table 3. For WindTrax, high linearity was observed between any pair of data sets, with $\mathrm{R}^{2}$ values ranging from 0.88 to 1.00 . It was observed that the highest linearity was determined when comparing any two data sets as long as they had the same lowest measurement height—e.g., data sets 3 and 1 both with the lowest height at $2.0 \mathrm{~m}$, data sets 4 and 2 both with the lowest

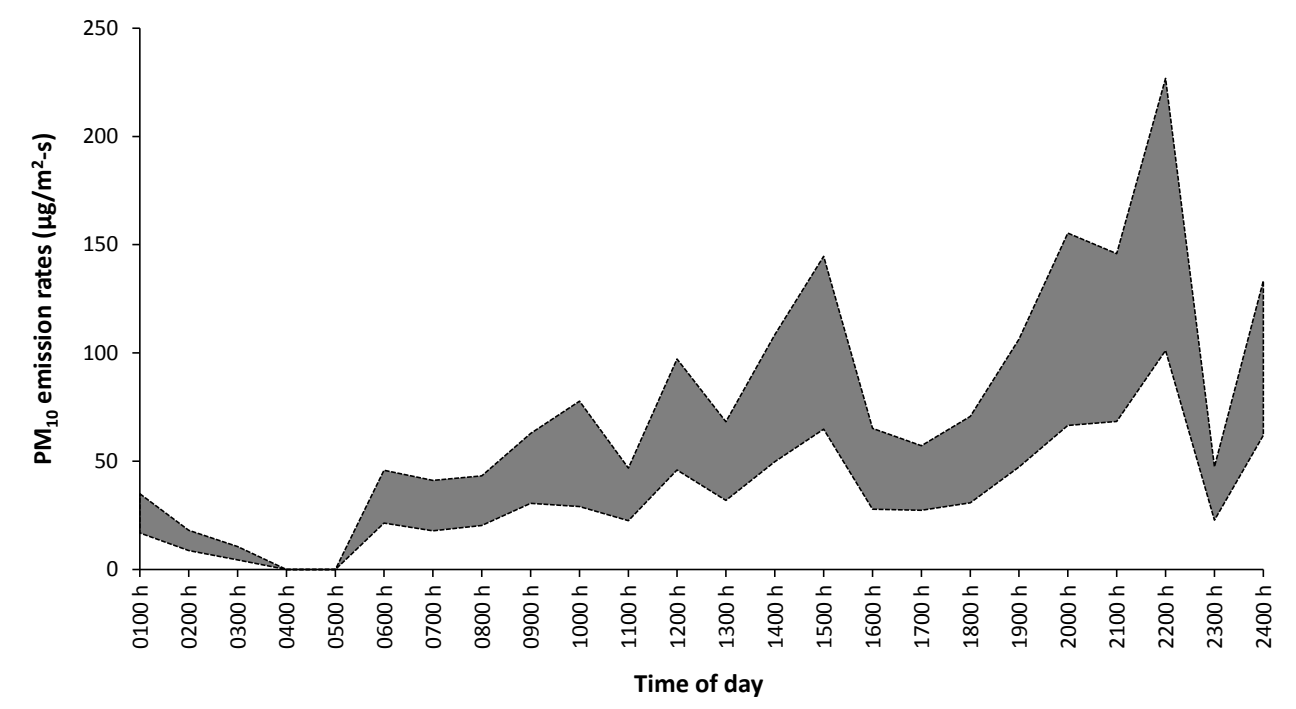

Figure 4. Hourly median $\mathrm{PM}_{10}$ emission rates calculated with WindTrax. Shaded area represents the range of emission estimates calculated using all the eight data sets.

Table 3. Linear regression between any two data sets $(x, y)$ applied in WindTrax in terms of determined $\mathrm{PM}_{10}$ emission rates. $^{\text {a,b }}$

\begin{tabular}{|c|c|c|c|c|c|c|c|}
\hline Data set $y \backslash$ Data set $x$ & 1 & 2 & 3 & 4 & 5 & 6 & 7 \\
\hline 2 & $0.91(0.97)$ & & & & & & \\
\hline 3 & $1.01(1.00)$ & $1.10(0.95)$ & & & & & \\
\hline 4 & $0.92(0.97)$ & $1.00(1.00)$ & $0.90(0.97)$ & & & & \\
\hline 5 & $1.06(0.99)$ & $1.14(0.92)$ & $1.04(0.99)$ & $1.13(0.93)$ & & & \\
\hline 6 & $1.05(0.99)$ & $1.13(0.93)$ & $1.03(1.00)$ & $1.12(0.95)$ & $0.99(1.00)$ & & \\
\hline 7 & $0.95(0.98)$ & $1.04(0.98)$ & $0.93(0.98)$ & $1.03(0.99)$ & $0.89(0.94)$ & $0.90(0.96)$ & \\
\hline 8 & $1.10(0.97)$ & $1.18(0.88)$ & $1.08(0.98)$ & $1.18(0.90)$ & $1.05(1.00)$ & $1.05(0.99)$ & $1.15(0.92)$ \\
\hline
\end{tabular}

${ }^{\mathrm{a}}$ In performing regression, data set $x$ was treated as the independent variable and data set $y$ as the dependent variable. ${ }^{\mathrm{b}}$ Values presented are slopes from regression analyses; values in parentheses are corresponding $\mathrm{R}^{2}$ values. 
height at $3.81 \mathrm{~m}$, etc. On the other hand, comparing any two data sets that differed in the lowest measurement height (i.e., one at $2.0 \mathrm{~m}$ while the other at $3.81-\mathrm{m}$ ) resulted to the lowest linearity. The percentage difference between any two data sets ranged from $0 \%$ to $18 \%$, with an average of $8 \%$. Similarly, the difference in calculated $\mathrm{PM}_{10}$ emission rates lowered when comparing any two data sets that had the same lowest measurement height whereas increased when the lowest measurement heights differed. In addition, the difference was largest when comparing the single-height measurement at 2.0-m (data set 8) to multiple-height measurements with the lowest height at 3.81-m (data sets 2 and 4) (Table 3).

\subsection{Flux-Gradient Technique-Based PM$_{10}$ Emission Rates}

Plotted in Figure 5 are ranges of hourly $\mathrm{PM}_{10}$ emission rates calculated with the flux-gradient technique using the first six data sets (1 to 6, Table 2 ) and four $\phi_{m}$ formulations (i.e., total of 24 data set- $\phi_{m}$ formulation combinations). Similarly, a diurnal trend in calculated $\mathrm{PM}_{10}$ emission rates was observed for all data set- $\phi_{m}$ formulation combinations, with the highest emission rates calculated for the $1900 \mathrm{~h}$ to $2200 \mathrm{~h}\left(44\right.$ to $\left.154 \mathrm{\mu g} / \mathrm{m}^{2} \cdot \mathrm{s}\right)$ and $1400 \mathrm{~h}$ to $1500 \mathrm{~h} \mathrm{(43} \mathrm{to} 102 \mu \mathrm{g} / \mathrm{m}^{2} \cdot \mathrm{s}$ ) periods. Unlike with WindTrax, however, exclusion of the $2.0-\mathrm{m}$ height measurement in emission estimation led to a slightly different profile - for combinations using data sets 2 and 4 , the $1400 \mathrm{~h}$ to $1500 \mathrm{~h}$ period ( 43 to $96 \mu \mathrm{g} / \mathrm{m}^{2} \cdot \mathrm{s}$ ) had higher $\mathrm{PM}_{10}$ emission rates than the 1900 to $2200 \mathrm{~h}$ period (44 to $81 \mu \mathrm{g} / \mathrm{m}^{2} \cdot \mathrm{s}$ ). Comparing data sets 1 and 2, exclusion of the 2.0-m height slightly increased $\phi_{m}$, and, equivalently, $K_{P M}$ (average of $32 \%$ ) but significantly lowered the calculated vertical $\mathrm{PM}_{10}$ concentration gradient (36\%). Between $1400 \mathrm{~h}$ to $1500 \mathrm{~h}$ and 1900 to $2200 \mathrm{~h}$ periods, it was the latter that had the largest decrease (48\%) in concentration gradient- -this explained why the $1900 \mathrm{~h}$ to $2200 \mathrm{~h}$ period no longer had the highest $\mathrm{PM}_{10}$ emission rates calculated for the day.

Overall median hourly $\mathrm{PM}_{10}$ emission rates for all data set- $\phi_{m}$ formulation combinations ranged from 27 to 47 $\mu \mathrm{g} / \mathrm{m}^{2} \cdot \mathrm{s}$, with the highest values derived when using data set 3-i.e., with the 2.0-m height (lowest) but without the 7.62-m height (highest). Among the four $\phi_{m}$ formulations, Hogstrom [35] produced the highest $\mathrm{PM}_{10}$ emissions rates whereas Flesch et al. [23] had the lowest. With respect to Hogstrom [35], Flesch et al. [23] resulted to emission rates lower by $10 \%$ to $12 \%$ while the other two differed by $1 \%$ to $3 \%$ only. This was not surprising as $a$ (Equation (5)) from Flesch $e t$ al. [23] had a setting less than half of those from the other three for unstable conditions (Table 1).

For the flux-gradient technique, slopes and $\mathrm{R}^{2}$ values from regression analyses are summarized in Table 4. Similar to WindTrax, the following applies for the flux-gradient technique: 1$)$ high linearity $\left(\mathrm{R}^{2}>0.74\right)$ was observed between any pair of data sets; 2 ) the highest linearity was obtained when comparing data sets with the same lowest measurement height (e.g., data sets 2 and 4, 1 and 5, etc.); and 3) the lowest linearity was determined when the data sets differed in the lowest measurement height (e.g., data sets 2 and 3, 3 and 4, etc.). Un-

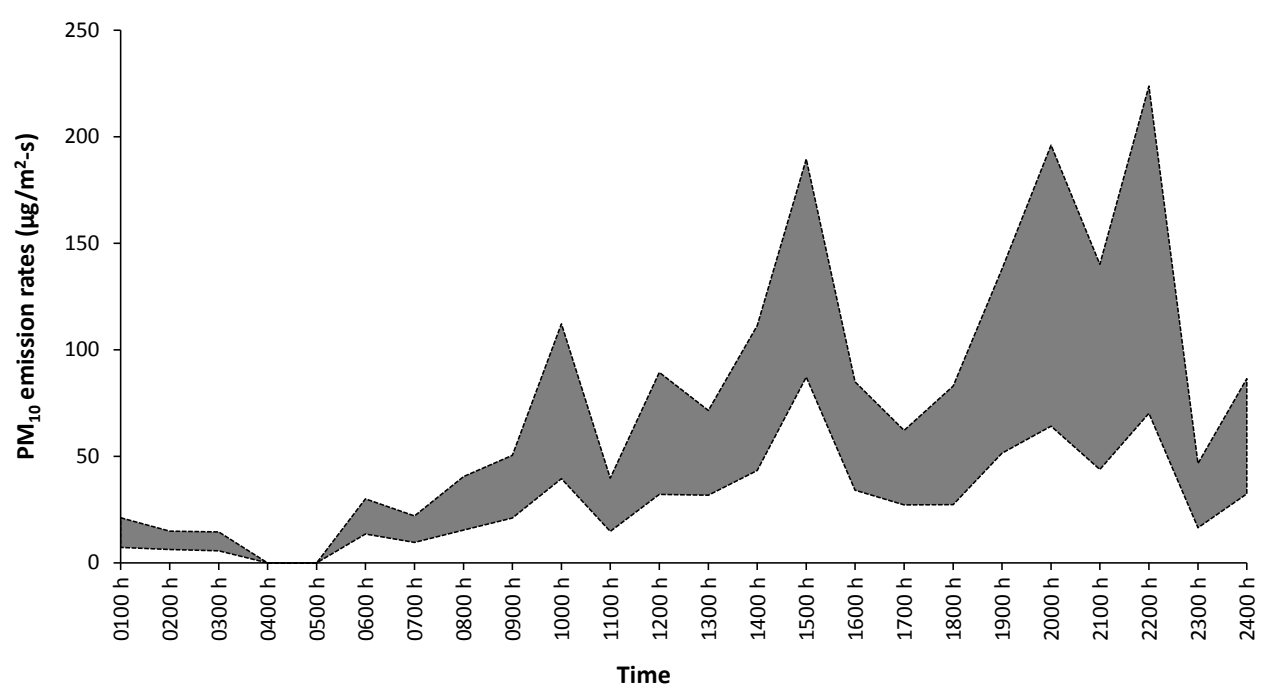

Figure 5. Hourly median $\mathrm{PM}_{10}$ emission rates calculated with the flux-gradient technique. Shaded area represents the range of emission estimates calculated using all the eight data sets. 
Table 4. Linear regression between any two data sets $(x, y)$ applied in the flux-gradient technique in terms of determined $\mathrm{PM}_{10}$ emission rates.

\begin{tabular}{cccccc}
\hline Data set $y$ /Data set $x$ & 1 & 2 & 3 & 4 & \\
\hline 2 & $0.77(0.86)$ & & & & \\
3 & $1.18(0.97)$ & $1.40(0.74)$ & & & \\
4 & $0.79(0.87)$ & $1.02(1.00)$ & $0.64(0.74)$ & & \\
5 & $0.96(1.00)$ & $1.16(0.85)$ & $0.80(0.98)$ & $1.14(0.85)$ & $1.16(0.98)$ \\
6 & $1.10(0.98)$ & $1.31(0.75)$ & $0.94(1.00)$ & $1.28(0.76)$ & $1.90)$
\end{tabular}

${ }^{\mathrm{a}}$ In performing regression, data set $x$ was treated as the independent variable and data set $y$ as the dependent variable; ${ }^{\mathrm{b}}$ Values presented are slopes from regression analyses; values in parentheses are corresponding $\mathrm{R}^{2}$ values.

like with WindTrax, use of different data sets, which varied in heights and number of heights included, led to larger difference $(<56 \%)$ in calculated emission rates (Table 4$)$. The lowest differences were obtained when comparing data sets 2 and 4 (2\%), data sets 1 and $5(4 \%)$, and data sets 3 and $6(6 \%)$ whereas the largest when comparing data sets 3 and 4 (56\%) and data sets 2 and 3 (40\%). In general, relatively higher $\mathrm{PM}_{10}$ emission rates were calculated when: 1) changing the lowest measurement height from $3.81 \mathrm{~m}$ to $2.0 \mathrm{~m}$ (e.g., data sets 4 and 5 ) or including the 2.0-m height (e.g., data sets 1 and 2), equivalent to what was observed with WindTrax; and 2) changing the highest measurement height from $7.62 \mathrm{~m}$ to $5.34 \mathrm{~m}$ (e.g., data sets 5 and 6) or excluding the 7.62-m height (e.g., data sets 1 and 3). Results also indicate that the most critical heights when implementing the flux-gradient technique would be the lowest and the highest measurement heights used in approximating the vertical concentration gradient and $K_{P M}$. As long as the lowest and the highest measurement heights remain the same, removal of heights in between would likely lead to very small change in estimated emission rate. Comparing data sets 2 and 4, 1 and 5, and 3 and 6, removal of other heights led only to 2\%, 4\%, and 6\% change in calculated $\mathrm{PM}_{10}$ emission rates, respectively (Table 4).

\subsection{Comparison of WindTrax and the Flux-Gradient Technique}

Previous studies reported that between WindTrax (bLS model) and the flux-gradient technique, it was the latter that tended to have the lower emission estimates [33] [38] [41]. In the present study, however, the flux-gradient technique produced the higher $\mathrm{PM}_{10}$ emission rates in general. This difference in findings could be attributed to difference in measurement design when implementing the flux-gradient technique, including measurement heights (i.e., 2.0 to $7.62 \mathrm{~m}$ range in this study, <2 $\mathrm{m}$ only in Wilson et al. [41] and Flesch et al. [33]), area source evaluated (i.e., feedlot in this study, lagoon in Wilson et al. [41]), emissions measured (i.e., $\mathrm{PM}_{10}$ in this study, gases/tracers in previous), comparison procedure (i.e., hourly data points in this study, seasonal and annual means in Todd et al. [38]), and approximation of eddy diffusivity (i.e., similar to companion studies [8] [18], the procedure implemented followed Prueger et al. [34]). As discussed below, the only time the fluxgradient technique gave the lower $\mathrm{PM}_{10}$ emission rates in this study was with the combination of data sets that excluded the 2.0-m height and $\phi_{m}$ formulations from Flesch et al. [23].

Slopes and $\mathrm{R}^{2}$ values from performing regression analyses between WindTrax and the flux-gradient technique are summarized in Table 5. In terms of their calculated $\mathrm{PM}_{10}$ emission rates, WindTrax and the flux-gradient technique had relatively high linear relationship $\left(0.73 \leq \mathrm{R}^{2} \leq 0.89\right)$. The highest linearity was observed between the two methods using data set 5-i.e., with two measurement heights, the lowest (2.0 m) and the highest (7.62 $\mathrm{m})$ in the measurement set-up. Based on slopes (Table 5), the percentage difference in estimated emission rate between WindTrax and the flux-gradient technique ranged up to $38 \%$. The lowest differences $(<8 \%)$ were observed when using data sets 2 and 4, which did not include the 2.0-m height measurements in emission estimation. Meanwhile, the difference was largest when using data set 3 (29\% to 38\%) followed by data set 6 (19\% to $27 \%$ ), both of which included the $2.0-\mathrm{m}$ height but excluded the 7.62-m height. These results suggest lower difference between WindTrax and the flux-gradient technique when estimating emission rates using the 7.62-m height and, in contrast, neglecting the 2.0-m height. Note that for both methods, use of the 2.0-m height measurements resulted to higher $\mathrm{PM}_{10}$ emission rate estimates-for the flux-gradient technique, this was due to lower $\phi_{m}$ and $K_{P M}$, and higher vertical concentration gradient calculated. And as mentioned above, use of the 
Table 5. Linear regression between WindTrax and the flux-gradient technique for all data set- $\phi_{m}$ formulation combinations $[24] .{ }^{\mathrm{a}, \mathrm{b}}$

\begin{tabular}{ccccc}
\hline Data set & \multicolumn{2}{c}{$\phi_{m}$ formulations } \\
\hline & Hogstrom [35] & Flesch et al. [23] & $\begin{array}{c}\text { Dyer and Hicks [36] } \\
\text { Dyer [39] }\end{array}$ & Hogstrom [37] \\
\hline 1 & $1.21(0.84)$ & $1.11(0.82)$ & $1.19(0.84)$ & $1.19(0.83)$ \\
2 & $1.03(0.76)$ & $0.93(0.73)$ & $1.01(0.75)$ & $1.00(0.75)$ \\
3 & $1.38(0.78)$ & $1.29(0.76)$ & $1.36(0.78)$ & $1.36(0.78)$ \\
4 & $1.05(0.77)$ & $0.95(0.75)$ & $1.03(0.77)$ & $1.02(0.77)$ \\
5 & $1.11(0.89)$ & $1.03(0.87)$ & $1.09(0.89)$ & $1.09(0.89)$ \\
\hline
\end{tabular}

${ }^{\mathrm{a}}$ For comparison purposes, WindTrax was treated as the independent variable and the flux-gradient technique as the dependent variable in the regression analyses; 'Values presented are slopes from regression analyses; values in parentheses are corresponding $\mathrm{R}^{2}$ values.

7.62-m height, which considerably reduced the estimated vertical concentration gradient, significantly lowered the emission rate calculated by the flux-gradient technique.

In terms of their calculated $\mathrm{PM}_{10}$ emission rates, WindTrax and the flux-gradient technique were not significantly different $(0.05<\mathrm{P}<0.90)$ from each other when using data sets 2,4 , and 5 , the first two as the data sets that did not include the $2.0-\mathrm{m}$ measurement height. For data set 1 , in which all the four measurement heights were used, $\phi_{m}$ formulation from Flesch et al. [23], when used in the flux-gradient technique, was the only one in which the two methods did not significantly vary $(\mathrm{P}=0.09)$ in estimated emission rates. To have closer estimates with WindTrax, the suggested $\phi_{m}$ formulation for data sets that included the 2.0-m height was the one from Flesch et al. [23] based on regression analyses and paired t-test. For data sets 2 and 4 (i.e., no 2.0-m height), the suggested $\phi_{m}$ formulation was the one from Hogstrom [37], followed by Dyer [39] and Dyer and Hicks [36] in second, and Hogstrom [35] in third—still, these three formulations produced $\mathrm{PM}_{10}$ emission estimates that were not significantly different from each other $(\mathrm{P} \geq 0.41)$. Nevertheless, regardless of $\phi_{m}$ formulations for the flux-gradient technique, the high linearity observed indicates the possibility of developing conversion factors between the two emission estimation methods.

\section{Conclusions}

This study compared WindTrax and the flux-gradient technique as methods for estimating $\mathrm{PM}_{10}$ emissions from large commercial beef cattle feedlots. Using $\mathrm{PM}_{10}$ concentration measurements at several heights and measured meteorological conditions at a Kansas cattle feedlot, the two emission estimation methods were compared using different concentration data sets, which varied in terms of heights and number of heights included, and several formulations for the flux-gradient technique's nondimensional correction parameter $\phi_{m}$. From the analyses, the following conclusions were made:

- Between the two methods, WindTrax was least sensitive to changes in heights and number of heights used in calculating emission rates. In this study, percent change in $\mathrm{PM}_{10}$ emission rates estimated by WindTrax ranged up to $18 \%$, which was relatively small compared to the change observed for the flux-gradient technique $(\leq 56 \%)$. Still, in each method, high linearity was observed among $\mathrm{PM}_{10}$ emission rates calculated using different concentration data sets.

- For both methods, higher $\mathrm{PM}_{10}$ emission rates were obtained when using the 2.0-m height, the lowest height in the measurement set-up, in emission estimation. On the other hand, $\mathrm{PM}_{10}$ emission rates calculated with the flux-gradient technique lowered when using the 7.62-m height, the highest height in the set-up.

- For the flux-gradient technique, the most critical heights were the lowest and the highest heights used in calculating the vertical concentration gradient. As demonstrated in this study, neglecting other heights in between resulted only in percent change of $2 \%$ to $6 \%$.

- In general, the flux-gradient technique produced the higher $\mathrm{PM}_{10}$ emission rates. Only by excluding the 2.0-m height and using $\phi_{m}$ formulations from Flesch et al. [23] made the flux-gradient technique calculate 
emission rates lower, but not significantly different, than those by WindTrax.

- For all $\phi_{m}$ formulations evaluated, the smallest difference in estimated $\mathrm{PM}_{10}$ emission rates was observed between WindTrax and the flux-gradient when using data sets without the 2.0 -m height $(\leq 8 \%)$. It should also be pointed out, however, that in this study, the flux-gradient technique was implemented with a very strict criterion for linearity (Pearson correlation $=0.95$ ) between $\mathrm{PM}_{10}$ concentration and measurement height. Using a lower criterion would likely lead to higher difference in calculated $\mathrm{PM}_{10}$ emission rates between the two methods (e.g., Pearson correlation $=0.75$ increased the difference by $50 \%$ ).

Results from this study could serve as reference for and in developing conversion factors between WindTrax and the flux-gradient technique. The procedures presented for both methods can be used in determining PM emission rates from large commercial cattle feedlots. It must be emphasized, however, that the version of WindTrax implemented neglected gravitational settling effects; as noted, this might underestimate $\mathrm{PM}_{10}$ emissions by $4 \%$. Based on meteorological conditions measured at the cattle feedlot studied, the flux-gradient technique was found to be applicable in estimating emission rates for PM with aerodynamic diameter $\leq 35 \mu \mathrm{m}$ [8]; above this range, it is recommended to utilize a different emission estimation method that can account for gravitational settling effects.

\section{Acknowledgements}

This study was supported by USDA National Institute of Food and Agriculture (Project No. 2009-35112-05244), USDA Agricultural Research Service, and Kansas Agricultural Experiment Station (contribution number 14410-J). Technical assistance provided by the following is acknowledged: Darrell Oard, Dr. Li Guo, Dr. Orlando Aguilar, Dr. Howell Gonzales, and Curtis Leiker, formerly of Kansas State University, Manhattan, KS; Dr. Kenwood Scoggin of USDA, Agricultural Research Service, Ames, IA; and Dr. Bernardo Predicala of Prairie Swine Centre Inc., Saskatoon, Saskatchewan, Canada. Cooperation of feedlot operators and KLA Environmental Services, Inc. is also acknowledged.

\section{References}

[1] Flesch, T.K., Wilson, J.D., Harper, L.A., Todd, R.W. and Cole, N.A. (2007) Determining Ammonia Emissions from a Cattle Feedlot with an Inverse Dispersion Technique. Agricultural and Forest Meteorology, 144, 139-155. http://dx.doi.org/10.1016/j.agrformet.2007.02.006

[2] Todd, R.W., Cole, N.A., Rhoades, M.B., Parker, D.B. and Casey, K.D. (2011) Daily, Monthly, Seasonal and Annual Ammonia Emissions from Southern High Plains Cattle Feedyards. Journal of Environmental Quality, 40, 1-6. http://dx.doi.org/10.2134/jeq2010.0307

[3] Baek, B.H., Todd, R., Cole, N.A. and Koziel, J.A. (2006) Ammonia and Hydrogen Sulphide Flux and Dry Deposition Velocity Estimates Using Vertical Gradient Method at a Commercial Beef Cattle Feedlot. International Journal of Global Environmental Issues, 6, 189-203. http://dx.doi.org/10.1504/IJGENVI.2006.010154

[4] Hutchinson, G.L., Mosier, A.R. and Andre, C.E. (1982) Ammonia and Amine Emissions from a Large Cattle Feedlot. Journal of Environmental Quality, 11, 288-293. http://dx.doi.org/10.2134/jeq1982.00472425001100020028x

[5] Aguilar, O.A., Maghirang, R., Rice, C.W., Trabue, S.L. and Erickson, L.E. (2014) Nitrous Oxide Fluxes from a Commercial Beef Cattle Feedlot in Kansas. Air, Soil and Water Research, 7, 35-45. http://dx.doi.org/10.4137/ASWR.S12841

[6] McGinn, S.M., Chen, D., Loh, Z., Hill, J., Beauchemin, K.A. and Denmead, O.T. (2008) Methane Emissions from Feedlot Cattle in Australia and Canada. Australian Journal of Experimental Agriculture, 48,183-185. http://dx.doi.org/10.1071/EA07204

[7] Trabue, S., Scoggin, K., McConnell, L., Maghirang, R., Razote, E. and Hatfield, J. (2011) Identifying and Tracking Key Odorants from Cattle Feedlots. Atmospheric Environment, 45, 4243-4251. http://dx.doi.org/10.1016/j.atmosenv.2011.04.081

[8] Bonifacio, H.F., Maghirang, R.G., Trabue, S.L., McConnell, L.L., Prueger, J.H. and Razote, E.B. (2013) Particulate Emissions from a Beef Cattle Feedlot Using the Flux-Gradient Technique. Journal of Environmental Quality, 42, 1341-1352. http://dx.doi.org/10.2134/jeq2013.04.0129

[9] McGinn, S.M., Flesch, T.K., Chen, D., Crenna, B., Denmead, O.T., Naylor, T. and Rowell, D. (2010) Coarse Particulate Matter Emissions from Cattle Feedlots in Australia. Journal of Environmental Quality, 39, 791-798. http://dx.doi.org/10.2134/jeq2009.0240

[10] National Research Council (2003) Air Emissions from Animal Feeding Operations: Current Knowledge, Future Needs. 
National Academy of Sciences, Washington, D.C.

[11] USEPA (2005) Animal Feeding Operations Consent Agreement and Final Order. OAR-2004-0237, FRL-7864-4.

[12] USEPA (2012) Development of Emissions-Estimating Methodologies for Broiler Operations_Draft.

[13] USEPA (2012) Development of Emissions-Estimating Methodologies for Lagoons and Basins at Swine and Dairy Animal feeding operations-Draft.

[14] USEPA (2011) Call for Information: Information Related to the Development of Emission-Estimating Methodologies for Animal Feeding Operations. Code of Federal Regulations, Part 60, Title 40. Fed. Regist. 76:3060.

[15] Baum, K.A., Ham, J.M., Brunsell, N.A. and Coyne, P.I. (2008) Surface Boundary Layer of Cattle Feedlots: Implications for Air Emissions Measurement. Agricultural and Forest Meteorology, 148, 1882-1893. http://dx.doi.org/10.1016/j.agrformet.2008.06.017

[16] Flocchini, R.G., James, T.A., Ashbaugh, L.L., Brown, M.S., Carvacho, O.F., Holmen, B.A., Matsumura, R.T., TrzeplaNabaglo, K. and Trubamoto, C. (2001) Interim Report: Sources and Sinks of $\mathrm{PM}_{10}$ in the San Joaquin Valley. California_Crocker Nuclear Laboratory, UC-Davis. http://www.arb.ca.gov/research/sapr/reports/l2022.pdf

[17] Bonifacio, H.F., Maghirang, R.G., Razote, E.B., Trabue, S.L. and Prueger, J.H. (2013) Comparison of AERMOD and WindTrax Dispersion Models in Determining $\mathrm{PM}_{10}$ Emission Rates from a Beef Cattle Feedlot. Journal of the Air \& Waste Management Association, 63, 545-556. http://dx.doi.org/10.1080/10962247.2013.768311

[18] Bonifacio, H.F., Maghirang, R.G., Trabue, S.L., McConnell, L.L., Prueger, J.H. and Bonifacio, E.R. (2015) TSP, PM 10 , and $\mathrm{PM}_{2.5}$ Emissions from a Beef Cattle Feedlot Using the Flux-Gradient Technique. Atmospheric Environment, 101, 49-57. http://dx.doi.org/10.1016/j.atmosenv.2014.11.017

[19] USEPA (2001) Procedures Document for National Emission Inventory, Criteria Pollutants 1985-1999. EPA-454/R01-006.

[20] Auvermann, B.W., Bush, K.J., Marek, G.W., Heflin, K., Wilhite, W.B. and Sakirkin, S.L.P. (2010) Time-Varying $\mathrm{PM}_{10}$ Emissions from Open-Lot Dairies and Cattle Feedyards. International Symposium on Air Quality and Manure Management for Agriculture, Dallas, 13-16 September 2010, Paper 711P0510cd.

[21] Countess Environmental (2006) Western Regional Air Partnership (WRAP) Fugitive Dust Handbook Contract No. 30201-111. Western Governors’ Association, Denver.

[22] Wanjura, J.D., Parnell, C.B., Shaw, B.W. and Lacey, R.E. (2004) A Protocol for Determining a Fugitive Dust Emission Factor from a Ground Level Area Source. American Society of Agricultural Engineers (ASAE) Proceedings, Ontario, 1-4 August 2004, Paper 044018.

[23] Flesch, T.K., Wilson, J.D., Harper, L.A., Crenna, B.P. and Sharpe, R.R. (2004) Deducing Ground-to-Air Emissions from Observed Trace Gas Concentrations: A Field Trial. Journal of Applied Meteorology, 43, 487-502. http://dx.doi.org/10.1175/1520-0450(2004)043<0487:DGEFOT>2.0.CO;2

[24] Flesch, T.K. and Wilson, J.D. (2005) Estimating Tracer Emission with a Backward Lagrangian Stochastic Technique. In: Micrometeorology in Agricultural Systems, Agronomy Monograph no. 47, American Society of Agronomy, Inc., Crop Science Society of America, Inc., Soil Science Society of America, Inc., Wisconsin, 513-531.

[25] Flesch, T.K., Wilson, J.D. and Yee, E. (1995) Backward-Time Lagrangian Stochastic Models and Their Application to Estimate Gaseous Emissions. Journal of Applied Meteorology, 34, 1320-1332. http://dx.doi.org/10.1175/1520-0450(1995)034<1320:BTLSDM>2.0.CO;2

[26] Crenna, B. (2006) An Introduction to WindTrax. Department of Earth and Atmospheric Science, University of Alberta, Canada.

[27] Crenna, B. (2006) Atmospheric Data in WindTrax. Department of Earth and Atmospheric Science, University of Alberta, Canada.

[28] Flesch, T.K., Wilson, J.D., Harper, L.A. and Crenna, B.P. (2005) Estimating Gas Emissions from a Farm with an Inverse-Dispersion Technique. Atmospheric Environment, 39, 4863-4871. http://dx.doi.org/10.1016/j.atmosenv.2005.04.032

[29] Denmead, O.T. (2008) Approaches to Measuring Fluxes of Methane and Nitrous Oxide between Landscapes and the Atmosphere. Plant Soil, 309, 5-24. http://dx.doi.org/10.1007/s11104-008-9599-z

[30] Meyers, T.P. and Baldocchi, D.D. (2005) Current Micrometeorological Flux Methodologies with Applications in Agriculture. In: Micrometeorology in Agricultural Systems, Agronomy Monograph no. 47, American Society of Agronomy, Inc., Crop Science Society of America, Inc., Soil Science Society of America, Inc., Wisconsin, 381-396.

[31] Prueger, J.H. and Kustas, W.P. (2005) Aerodynamic Methods for Estimating Turbulent Fluxes. In: Micrometeorology in Agricultural Systems, Agronomy Monograph no. 47, American Society of Agronomy, Inc., Crop Science Society of America, Inc., Soil Science Society of America, Inc., Wisconsin, 407-436.

[32] Lilly, G.E. (1973) Effect of Particle Size on Particle Eddy Diffusivity. Industrial \& Engineering Chemistry Funda- 
mentals, 12, 268-275. http://dx.doi.org/10.1021/i160047a002

[33] Flesch, T.K., Prueger, J.H. and Hatfield, J.L. (2002) Turbulent Schmidt Number from a Tracer Experiment. Agricultural and Forest Meteorology, 111, 299-307. http://dx.doi.org/10.1016/S0168-1923(02)00025-4

[34] Prueger, J.H., Gish, T.J., McConnell, L.L., McKee, L.G., Hatfield, J.L. and Kustas, W.P. (2005) Solar Radiation, Relative Humidity, and Soil Water Effects on Metolachlor Volatilization. Environmental Science \& Technology, 39, 52195226. http://dx.doi.org/10.1021/es048341q

[35] Hogstrom, U. (1996) Review of Some Basic Characteristics of the Atmospheric Surface Layer. Boundary-Layer Meteorology, 78, 215-246. http://dx.doi.org/10.1007/BF00120937

[36] Dyer, A.J. and Hicks, B.B. (1970) Flux-Gradient Relationships in the Constant Flux Layer. Quarterly Journal of the Royal Meteorological Society, 96, 715-721. http://dx.doi.org/10.1002/qj.49709641012

[37] Hogstrom, U. (1988) Non-Dimensional Wind and Temperature Profiles in the Atmospheric Surface Layer: A ReEvaluation. Boundary-Layer Meteorology, 42, 55-78. http://dx.doi.org/10.1007/BF00119875

[38] Todd, R.W., Cole, N.A., Harper, L.A., and Flesch, T.K. (2007) Flux-Gradient Estimates of Ammonia Emissions from Beef Cattle Feedyard Pens. International Symposium on Air Quality and Waste Management for Agriculture, Broomfield, 16-19 September 2007, Paper 701P0907cd.

[39] Dyer, A.J. (1974) A Review of Flux-Profile Relationships. Quarterly Journal of the Royal Meteorological Society, 87, 401-412. http://dx.doi.org/10.1002/qj.49708737311

[40] Hsieh, C.I., Katul, G. and Chi, T. (2000) An Approximate Analytical Model for Footprint Estimation of Scalar Fluxes in Thermally Stratified Atmospheric Flows. Advances in Water Resources, 23, 765-772. http://dx.doi.org/10.1016/S0309-1708(99)00042-1

[41] Wilson, J.D., Flesch, T.K. and Harper, L.A. (2001) Micro-Meteorological Methods for Estimating Surface Exchange with a Disturbed Windflow. Agricultural and Forest Meteorology, 107, 207-225. http://dx.doi.org/10.1016/S0168-1923(00)00238-0 